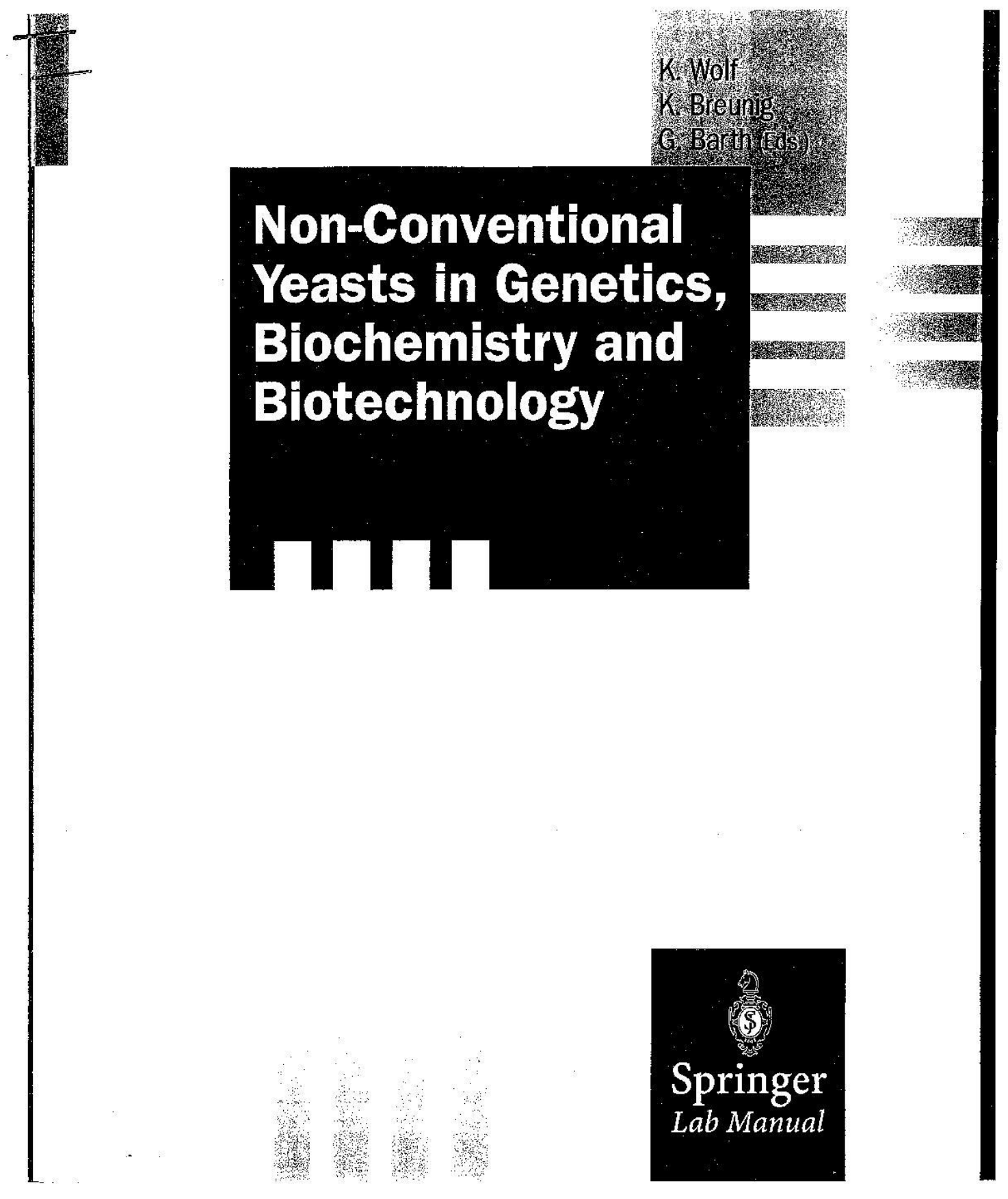

http://books.google.pt/books?id=SdaTt1r AtUC\&printsec=frontcover\&hl=ptPT\&source $=g b s$ ge summary $r \& c a d=0 \# v=$ onepage $\& q \& f=f a l s e$ 


\title{
Lipase Assay in Yarrowia lipolytica
}

\author{
Matías Morín, Francrsco J. Gonzalez, Altino Choupina, \\ Francisco J. Burguillo, and Angel Domínguez
}

\section{鿆 Aim}

To analyze lipase production in any Yarrowia lipolytica strain.

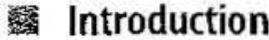

Lipases (triacylglycerol acyl hydrolases, EC 3.1.1.3) are key enzymes in fat metabolism produced by microorganisms, plants, and animals that catalyze the breakdown of triacylglycerols to free fatty acids and glycerol. In $\mathrm{Y}$. lipolytica several genes encoding lipases have been isolated, LIP2 coding for a secreted lipase (Pignede et al. 2000) and LIP1 and LIP3 encoding two lipase genes of the carboxylesterase family (Choupina et al. 1999). Lipase expression was repressed by glucose and induced by fatty acids and olive oil.

Matías Morín, Francisco J. Gonzalez, Angel Dominguez ( $\otimes)$

Tel.: +34-923-294677; Fax: +34-923-224876; e-mail: ado@usal.es

Departamento de Microbiología y Genética, Instituto de Microbiología

Bioquímica/CSIC, Universidad de Salamanca, 37071 Salamanca, Spain

Altino Choupina, Departamento de Biología, Escola Superior Agraria de Bragança, Portugal

Francisco J. Burguillo, Departamento de Química Física, Universidad de Salamanca, Spain 
Materials

Strains Any Yarrowia lipolytica strain

Media - YED medium: I \% yeast extract (Difco), $1 \%$ glucose

- MM medium: $0.67 \%$ yeast nitrogen base w/o amino acids (Difco); $1 \%$ glucose

- YNB/olive oil: $0.67 \%$ yeast nitrogen base $w / 0$ amino acids (Difco), $0.3 \%$ glucose (w/v), $0.7 \%$ olive oil; $200 \mathrm{mM}$ Tris-HCl buffer, $\mathrm{pH} 7.5$

- Agar/tributyrin: $0.67 \%$ yeast nitrogen base w/o amino acids (Difco); $0.3 \%$ glucose; $0.2 \%$ tributyrin; $200 \mathrm{mM}$ Tris- $\mathrm{HCl}$ buffer, $\mathrm{pH} 7.5 ; 2 \%$ agar

- Agar/tributyrin/glucose: $1 \%$ yeast extract (Difco); $0.2 \%$ tributyrin; $0.3 \%$ glucose; $200 \mathrm{mM}$ Tris-HCl buffer, $\mathrm{pH} 7.5 ; 2 \%$ agar

- Tributyrin should be sterilized alone by filtration. Solutions are mixed at $55^{\circ} \mathrm{C}$ and shaken to homogenize for $5 \mathrm{~min}$.

Reagents - Tributyrin (Sigma)

- Sigma lipase substrate (SLS), 62314 (Peled and Krenz 1981)

- p-Nitrophenyl butyrate (Sigma)

- Olive oil (Sigma)

- Acetone

- Emulsifying mixture $300 \mathrm{mM} \mathrm{NaCl} ; 3 \mathrm{mM} \mathrm{K}_{2} \mathrm{PO}_{4} ; 0.54 \%$ glycerol; $0.6 \%$ gum arabic

- $p$-Nitrophenyl butyrate ( $p$-NPB) $0.42 \mathrm{mM} p$-NPB; $0.05 \mathrm{M}$ phosphate buffer, $\mathrm{pH} 7.3 ; 4 \%$ acetone

Lipase activity assays

Solid media

Cells collected from cultures under the desired conditions are washed and resuspended in sterile water at a concentration of $10^{9}$ cells $/ \mathrm{mL}$. $10 \mu \mathrm{L}$ of this solution are placed on agar/tributyrin/glucose and/or agar/tributyrin plates and halo diameters are measured $48 \mathrm{~h}$ post-incubation at $28^{\circ} \mathrm{C}$ (Fig. 1). Lipase activity is quantified as the ratio between the squared diameter of 


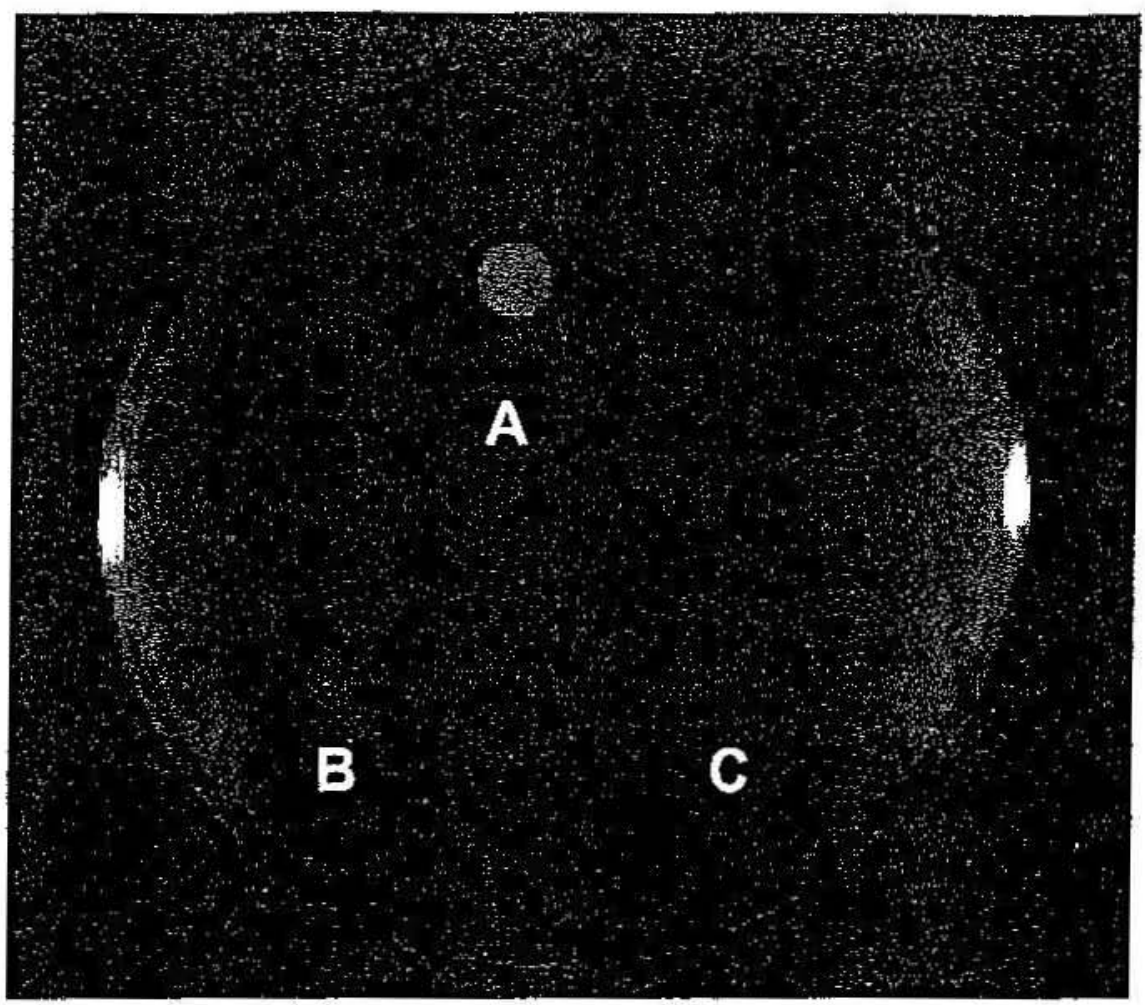

Fig. 1. Lipase production of different yeast species in solid medium (agar/tributyrin). A Yarrowia lipolytica (the halo is clearly visible), B Saccharomyces cerevisiae $\$ 288 \mathrm{C}$, and C Kluyveromyces lactis CBS2359

the halo and the squared diameter of the cell colony (the squared values come from comparing the surface of two circles).

Titration assays (potentiometric or pH-Stat method)

This method involves the mixing of a glyceride substrate in emulsion form with the enzyme at the optimum $\mathrm{pH}$ and temperature of the enzyme. During incubation, free fatty acids ate released by hydrolysis; which lowers the $\mathrm{pH}$ of the system. Automatic titration with $\mathrm{NaOH}$ then gives a direct measurement of the lipase activity. Three substrates are suitable for this assay: Sigma lipase substrate (SLS), tributyrin and olive oil. SLS is an emulsified substrate (commercially emulsified olive oil) but pure tributyrin and olive oil must be emulsified before the assay. The emulsifying agent is a solution prevared as following: $17.9 \mathrm{~g} \mathrm{NaCl}, 0.41 \mathrm{~g} \mathrm{KH}_{2} \mathrm{PO}_{4}, 400 \mathrm{~mL}$ water and $540 \mathrm{~mL}$ 
glycerol are mixed strongly; $6 \mathrm{~g}$ of gum arabic and water up to $1000 \mathrm{ml}$ are added and the mixture shaken until complete dissolution. The emulsifiec substrates are prepared as a mixture of $\mathrm{I} 5 \mathrm{~mL}$ of substrate (tributyrin or olive oil), $50 \mathrm{~mL}$ of the above emulsifying agent and $235 \mathrm{~mL}$ water. The mix. ture is shaken to homogeneity by hand and re-shaken before each assay.

The release of acid is continuously titrated at $\mathrm{pH} 7.2$ with the aid of : $\mathrm{pH}$-Stat, the RTS 822 recording titration system from Radiometer (Copenhagen, Denmark). The general $\mathrm{pH}$-Stat procedure is as follows: The reactior vessel containing $4.8 \mathrm{~mL}$ of the emulsified substrate is thermostatted a $25^{\circ} \mathrm{C}$ for $5 \mathrm{~min}$, after which $\mathrm{pH}$ is adjusted by the autoburet of the equip. ment to a fixed constant vaiue of 7.2. Finally, $0.1 \mathrm{~mL}$ of supernatant of the growth cultures or $0.1 \mathrm{~mL}$ of the appropriate cell solutions (to leave 10 ; cells $/ \mathrm{mL}$ in the reaction mixture) is injected into the vessel and the kinetic run is begun. Lipase activity is measured by recording the amount of titrat. ing $\mathrm{NaOH}(10-25 \mathrm{mM})$ added to maintain the $\mathrm{pH}$ at the fixed value against the reaction time (10-30 min in total). Activity is expressed as the initia rate and calculated as:

$\mathrm{v}(\mu \mathrm{mol} / \mathrm{L} / \mathrm{min})=(\Delta \mathrm{x} / \Delta \mathrm{y}) \mathrm{Mf}$

where $\Delta x / \Delta y$ is the initial slope of the kinetic curve determined graphically: $\mathrm{M}$ is the $\mathrm{NaOH}$ concentration in $\mathrm{mol} / \mathrm{L}$, and $\mathrm{f}$ is a scaling factor that takes into account the rate of the recorder, the volume of the vessel, and the conversion factors for units.

\section{Spectophotometric assay}

This involves the use of a chromogenic substrate, such as p-nitropheny. butyrate ( $p$-NPB) in solution, which upon hydrolysis yields colored $p$-nitrophenol as the reaction product. The substrate at $0.42 \mathrm{mM}$ is prepared as a mixture of $3.6 \mu \mathrm{L}$ of pure $p$-nitrophenyl butyrate, $48 \mathrm{~mL}$ of $0.05 \mathrm{M}$ phosphate buffer, $\mathrm{pH} 7.3$, and $2 \mathrm{~mL}$ of acetone as dispersing agent. The reactior: mixture contains $2.4 \mathrm{~mL}$ of substrate and $0.1 \mathrm{~mL}$ of supernatant of the growth cultures or $0.1 \mathrm{~mL}$ of the appropriate cell solutions (to leave 10: cells $/ \mathrm{mL}$ in the reaction mixture). The reaction is followed by recording absorbance at $400 \mathrm{~nm}$ with time (10 min) using a Beckman DU-7 spectrophotometer equipped with software to yield a least-squares fitting of the initial straight line of the kinetic run. The reaction mixture is stirred by means of a Cuv-O-Stir 333 magnetic microstirrer. A Selecta 389 thermostal with external circulation is used to maintain a constant temperature $\left(25.0^{\circ} \mathrm{C}\right)$ 
Activity is expressed as initial rate, calculated as:

$\mathrm{v}=1 / \varepsilon\left(\mathrm{dA}_{410} / \mathrm{dt}\right)$

where $\varepsilon$ is the extinction coefficient of $p$-NP at pH $7.3\left(1.01 \times 10^{4} \mathrm{~cm}^{-1} \mathrm{M}^{-1}\right)$ and $\mathrm{dA}_{410} / \mathrm{dt}$ is the initial slope of the absorbance-time curve.

\section{䌔 Experimental Procedure}

Grow a culture of $300 \mathrm{~mL}$ of one Y. lipolytica strain in $\mathrm{MM}$ at $28^{\circ} \mathrm{C}$ with Day 1 shaking (250 rpm) overnight.

Lipase induction in liquid medium. Cells in the exponential phase are col- Day 2 lected, washed and resuspended in $\mathrm{YNB} / \mathrm{olive}$ oil medium at $10^{6}$ cells $/ \mathrm{mL}$. Incubation is carried out at $28^{\circ} \mathrm{C}$ with shaking $(250 \mathrm{rpm}$ ). At the desired times aliquots are taken and activity determined either in whole cells or in supernatants. Usually maximal activity is reached after $32 \mathrm{~h}$ of incubation. Special attention must be paid to the correct buffering of the induction media since acidification of the medium will inactivate the lipase.

\section{鉦 References}

Choupina A, Gonzalez F, Morin M, Burguillo Fl, Fermiñan E, Dornínguez A (1999) The lipase system of Yarrowia lipolytica. Curr Genet 35:297

Peled N Krenz MC (1981) Assay of microbial lipases with emulsified trioleoyl glycerol; the fatty acids released are titrated with a p $\mathrm{H}$ stat. Anal Biochem 112:219-222

fatty acids released are titrated with a pt stat. Anal Biochem 112:219-222
pignede G, Wang HJ, Fudalej F, Gaillardin C, Seman M, Nicaud JM (2000) Characterization

of an extracellular lipase by LIP2 in Yarrowia lipolytica. I Bacteriol 182:2802-2810 

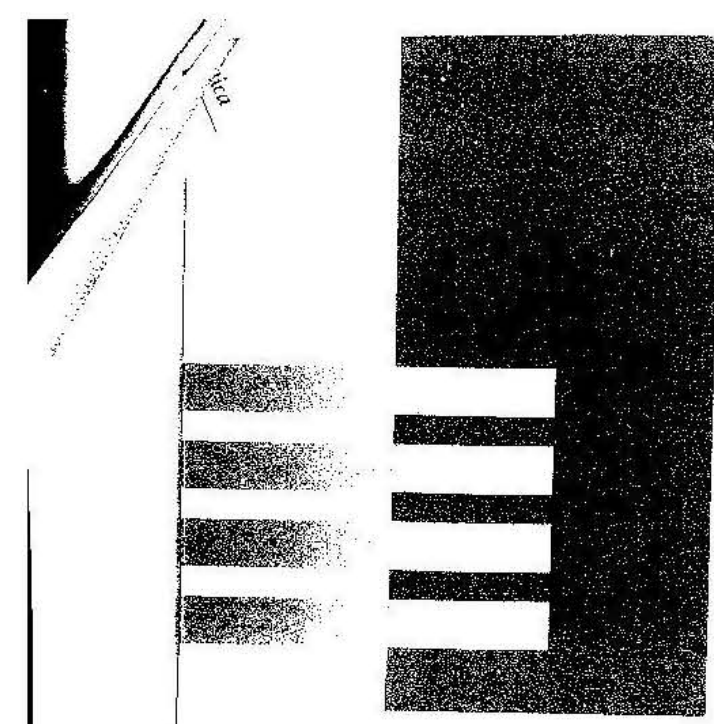

Non-Conventional Yeasts in Genetics, Biochemistry and Biotechnology

Most information on yeasts derives from experiments with the conventional yeasts Saccharomyces cerevisiae and Schizosaccharomyces pombe, the complete nuclear and mitochondrial genome of which has also been sequenced.

For all other non-conventional yeasts, investigations are in progress and the rapid development of molecular techniques has allowed an insight also into a variety of non-conventional yeasts.

in this bench manual, over 70 practical protocols using 15 different non-conventional yeast species and in addition several protocols of general use are described in detail. All of these experiments on the genetics, biochemistry and biotechnology of yeasts have been contributed by renowned laboratories and have been reproduced many times. The reliable protocols are thus ideally suited also for undergraduate and graduate practical courses. 